\title{
Determination of the furaltadone metabolite 5-methylmorpholino- 3-amino-2-oxazolidinone (AMOZ) using liquid chromatography coupled to electrospray tandem mass spectrometry during the nitrofuran crisis in Portugal
}

\author{
Jorge Barbosa $\cdot$ Maria Luz Ferreira • \\ Fernando Ramos · Maria Irene Noronha da Silveira
}

Received: 4 May 2007/ Accepted: 19 July 2007 / Published online: 6 September 2007

(C) Springer-Verlag 2007

\begin{abstract}
The use of nitrofuran veterinary drugs as antibacterial compounds in food-producing animals has been banned in the EU since 1995. As nitrofurans are extensive and rapidly metabolized, control of their illegal use in animal production must be done in edible tissues by LC-MS/MS analysis in order to determine persistent tissue-bound metabolites. The introduction during 2002 of the multiresidue detection of nitrofuran tissue-bound metabolites by LC-MS/MS for nitrofuran control in Portuguese Residues Monitoring Plan, revealed the presence of 5-morpholinomethyl-3-amino-2-oxozolidinone (AMOZ), the bound residue of furaltadone, in a large number of samples, namely in meat poultry samples. From the 226 analysed samples in the last 4 months of 2002, 78 were non-compliant due to the presence of AMOZ ( 61 broilers, 11 turkeys, 5 quails and 1 pig). In this context, the aim of this paper is to describe the analytical data obtained on meat samples collected from various animal species under official Portuguese control for nitrofuran drug residues during the so-called "Portuguese nitrofuran crisis".
\end{abstract}

Keywords Nitrofurans - Residue determination · Furaltadone metabolite $\cdot$ Meat $\cdot$ LC-MS/MS

Presented at the AOAC Europe Workshop, November 2006, Limassol, Cyprus.

J. Barbosa - M. L. Ferreira

LNIV, Laboratório Nacional de Investigação Veterinária,

Estrada de Benfica, 701, 1549-011 Lisboa, Portugal

F. Ramos $(\bowtie) \cdot$ M. I. N. da Silveira

Grupo de Bromatologia, Centro de Estudos Farmacêuticos,

Faculdade de Farmácia da Universidade de Coimbra,

3000-295 Coimbra, Portugal

e-mail: fjramos@ci.uc.pt

\section{Introduction}

The 5-nitrofurans, generally designated as nitrofurans, are synthetic chemotherapeutic agents with a broad antimicrobial spectrum; they are active against gram-positive (such as Staphylococcus, Streptococcus, Clostridium, and several Corynebacterium), gram-negative bacteria (such as Escherichia coli, Salmonella, Vibrio cholerae, Shigella, and Klebsiella), and some protozoans (such as Giardia, Histomonas meleagridis, Isopspora belli, Ballantidium coli, or Entamoeba histolytica). Their primary action is bacteriostatic, but at high doses they are also bactericidal [1-3].

Furazolidone, furaltadone, nitrofurazone and nitrofurantoin are the most important drugs in this group of compounds. They were used worldwide for five decades to control bacteria and protozoa, in massive treatments of swine and poultry, for morbidity and mortality reduction as a result of severe gastrointestinal and respiratory infections and in non-specific therapy of piglet enteritis necrosis. The great popularity of nitrofurans in intensive animal farm production was related to their low cost, generic availability, and great efficacy in the treatment of resistant infections.

Nitrofurans' carcinogenicity and mutagenicity has been widely investigated, particularly, in the case of furazolidone. Several studies concluded that the lateral side-chain, 3-amino-2-oxazolidinone (AOZ) is responsible for the inhibition of monoamine-oxidase (MAO) in rats after the administration of furazolidone; and that this compound's degradation by hydrolysis might produce $\beta$-hydroxyethylhydrazine, a compound with known mutagenic and carcinogenic properties [4]. The cytotoxicity and mutability from nitrofurans were also observed in mammal's cells [5]. 
Because of the doubts about the safety of nitrofurans and their residues in human health, in 1993 the European Union (EU) forbade the use of furaltadone, nitrofurantoin, and nitrofurazone in food production animals [6]. The provisional MRL for furazolidone was prolonged until 1995, and since the manufacturers could not provided further information about the safety of this compound and their bound metabolites, furazolidone was included in the Annex IV of the Council's Regulation (EEC) 2377/90 [7]. As a consequence, after January 1997 the nitrofurans were no longer allowed in the EU as veterinary drugs.

Studies concerning the detection of nitrofurans in food animals namely in swine and poultry have shown a rapid depletion of parent compounds in tissues, particularly, muscle, liver, and kidney due to their short in vivo half-life. Nitrofuran parent compounds were only sporadically detectable a few hours after cessation of the administration $[2,8,9]$. In vitro, the half-life of degradation process after the animals slaughter is different from tissue to tissue, but equally short. As a result, the possibility of detecting the parent administered drug within $24 \mathrm{~h}$ of the slaughter for control purposes is a remote possibility [10].

Nitrofuran's intense metabolism is responsible for the fast disappearance of parent compounds and the formation and accumulation of the respective biodegradation products. Studies carried out with radiolabelled furazolidone showed that part of the administered compound could not be extracted from tissues where it was bonded [8]. Subsequent studies have shown that furazolidone biodegradation results in the formation of reactive intermediates capable of binding to proteins and at least $70 \%$ of these bound metabolites contained AOZ [11, 12]. It was also possible to observe identical metabolic profiles for the other most important nitrofuran drugs: 5-metilmorpholino3-amino-2-oxazolidone (AMOZ), 1-amino-hydantoin (AHD), and semicarbazide (SEM), marker residues of furaltadone, nitrofurantoin, and nitrofurazone, respectively (Fig. 1).

In order to detect the presence of nitrofurans in biological samples from food animals, many sensitive and specific methods have been described, namely detection and quantification of furazolidone by LC-MS in porcine muscle [13], determination of furazolidone metabolite (AOZ) in liver, kidney and muscle from pigs by high performance liquid chromatography (HPLC) with ultra violet-diode array (UV-DAD) detection [12] or with thermospray LC-MS [14], analysis of furazolidone and furaltadone metabolites in pig liver by HPLC with UV detection and LC-MS [15] and determination of nitrofuran metabolites in animal tissues by liquid chromatographytandem mass spectrometry LC-MS/MS [16]. The high specificity and sensitivity demonstrated by LC-MS/MS for analysis of nitrofuran metabolites and the generalization of the use of this kind of equipment by residue laboratories around the world, has made possible to have an effective analytical procedure to control the long-term detection of illicit use of these compounds with detection levels ranging from 0.1 to $0.6 \mu \mathrm{g} / \mathrm{kg}$ [17].

The introduction of the method developed by RIKILT Wageningen and DARD Belfast as part of the FoodBRAND project into the laboratory routine for nitrofurans detection under the Portuguese Residues Monitoring Plan (PRMP), has exposed a previously unknown problem for the national authorities. This paper describes obtained analytical data on meat samples collected from various animal species under official Portuguese control for nitrofuran drug residues during 2002 and 2003, as well as the implemented follow-up measures.

\section{Experimental}

Reagents and materials

All reagents and solvents were of analytical grade or better unless stated otherwise. Methanol, hydrochloric acid, trisodium phosphate dodecahydrate, sodium hydroxide, ethyl acetate, acetic acid, and acetonitrile were supplied by Merck (Darmstadt, Germany). Ortho-nitrobenzaldehyde (o-NBA) was supplied by Sigma (Madrid, Spain). Water was demineralised using a Millipore purification system (Bedford, MA, USA).

Standards of 3-amino-2-oxazolidinone (AOZ), 5-methylmorfolino-3-amino-2-oxazolidinone (AMOZ), 1-aminohydantoin hydrochloride (AHD), 3-amino-2-oxazolidinone-fourth deuterated hydrochloride (AOZ-d4), and 5-methylmorfolino-3-amino-2-oxazolidinone-fith deuterated (AMOZ- d5) were supplied by VSD of Belfast (Veterinary Sciences Division, DARD, UK). The semicarbazide hydrochloride (SEM) was supplied by Sigma (Poole, Dorset, UK).

A Moulinex mincer (Lisbon, Portugal), a Mettler Toledo PC2000 and AE100 balances (Greifensee, Switzerland), a Memmert incubator (Buchenbach, Germany), a Heidolph Reax 2 overhead mixer (Schwabach, Germany), a Heraeus Megafuge 1.0 centrifuge (Hanau, Germany), a Turbovap Zymark evaporator (Hopkinton, MA, USA), and Whatman PVDF filters $(0.45 \mu \mathrm{m})$ Mini-Uniprep (Clifton, NJ, USA) were used to perform extraction and purification procedures.

The LC system (Agilent Technologies, Palo Alto, CA, USA) consisted of an HP1100 thermostatted autosampler, degasser, gradient pump, and thermostatted column compartment at $40{ }^{\circ} \mathrm{C}$. The LC column was a $150 \times 2 \mathrm{~mm}$ i.d. Agilent Zorbax XDB C18 (particle size $5 \mu \mathrm{m}$ ) with a $4 \times 2 \mathrm{~mm}$ i.d. Agilent Zorbax XDB C8, 5- $\mu \mathrm{m}$ guard column.

The LC column effluent was pumped to a 2 position 6 port Valco valve (Valco Instrument Co., Houston, TX, 
Fig. 1 Structures of furazolidone, furaldone, nitrofurantoin and nitrofurazone and their corresponding marker residues<smiles>CCCCN1CCOC1=O</smiles><smiles>O=C1OC(CN2CCOCC2)CN1/N=C/c1ccc([N+](=O)[O-])o1</smiles><smiles>O=C1CN(/N=C/c2ccc([N+](=O)[O-])o2)C(=O)N1</smiles><smiles>NC(=O)N/N=C/c1ccc([N+](=O)[O-])o1</smiles>

Nitrofurazone<smiles>NN1CCOC1=O</smiles>

3-Amino-2-oxazolidinone (AOZ)<smiles>NN1CC(CN2CCOCC2)OC1=O</smiles>

5-Methylmorpholino-3-amino-2-oxazolidinone<smiles>NN1CC(=O)NC1=O</smiles>

1-Amino-hydantoin (AHD)<smiles>NNC(N)=O</smiles>

Semicarbazide (SEM)
USA) before it reached the triple quadrupole tandem mass spectrometer Sciex API 3000 (Applied Biosystems, Foster City, CA, USA) equipped with a TurboIonSpray ion source. Data acquisition was controlled by Sciex Analyst ${ }^{\circledR}$ software, version 1.4.1.

The statistic calculations were performed using the package SPSS software, version 12.0.

\section{Standard solutions}

Individual stock standard solutions of the four nitrofuran metabolites (AOZ, AMOZ, AHD and SEM) and the two internal standards (AOZ-d4 and AMOZ-d5) were prepared at $50.0 \mathrm{mg} / \mathrm{L}$. All these stock standards solutions where stored at the refrigerator and were considered stable for, at least 6 months. Two composite standard working solutions were prepared at $50.0 \mu \mathrm{g} / \mathrm{L}$ : one with all the nitrofurans metabolites and other with the two internal standards. These standard working solutions were stored at the refrigerator and were shown to be stable for at least 1 month.

\section{Samples}

Meat samples from different animal species were mainly collected by the Portuguese Veterinary Authority (Direcção Geral de Veterinária-DGV) under the application of PRMP and on sequestered farms where animals tested positive for nitrofuran metabolites. After the declaration of an abnormal situation in the country concerning food safety involving the use of nitrofurans in food production animals, samples were also collected and analyzed under an Action Plan and a Contingency Plan, which were submitted to the European Commission by Portuguese Authorities.

All the samples (weighing between 50 and $100 \mathrm{~g}$ ) were collected in dark plastic bags. The samples were transported in frozen or refrigerated conditions and, after reception in the laboratory, were kept frozen $(T=-16$ to $-18^{\circ} \mathrm{C}$ ) until analysis.

\section{Sample preparation}

A portion of $1.0 \pm 0.05 \mathrm{~g}$ of minced and mixed muscle was weighed into a $15-\mathrm{L}$ screw top glass centrifuge tube. Then, $40 \mu \mathrm{L}$ of composite standard working solution of internal standards was added, homogenised, and let stand for about $15 \mathrm{~min}$. Afterwards, $5 \mathrm{~mL}$ of a $0.2 \mathrm{~mol} / \mathrm{L}$ hydrochloric acid solution and $50 \mu \mathrm{L}$ of a $0.1 \mathrm{~mol} / \mathrm{L} o$-NBA solution in methanol were added and the tube was closed and shaken by hand. The tube was then put in the Reax 2 agitator in the incubator and hydrolysis was done overnight at $T=37 \pm 2{ }^{\circ} \mathrm{C}$. After cooling, $500 \mu \mathrm{L}$ of a $0.3 \mathrm{~mol} / \mathrm{L}$ trisodium phosphate dodecahydrate solution was added to the sample and the $\mathrm{pH}$ was adjusted to $7 \pm 0.5$ with a $2 \mathrm{~mol} / \mathrm{L}$ sodium hydroxide solution. Then, $4 \mathrm{~mL}$ of ethyl acetate were added to the sample and the tube was shaken in the 
Reax 2 agitator for $20 \mathrm{~min}$. The sample was centrifuged at $1,200 \mathrm{~g}$ for $10 \mathrm{~min}$ and the organic layer was transferred to a 20-L centrifuge tube. The previous step was repeated and the two organic layers were mixed and evaporated to dryness at $T=45{ }^{\circ} \mathrm{C}$ under a nitrogen stream. The dry residue was dissolved in $500 \mu \mathrm{L}$ of 10:90 (v:v) acetonitrile:water with $0.1 \%$ of acetic acid solution, vortexed for $20 \mathrm{~s}$, and transferred to an autosampler LC amber vial through a PVDF $0.45 \mu \mathrm{m}$ filter.

For each batch of unknown samples, two blank meat samples (one as blank control and the other spiked with composite standard working solution of analytes in order to obtain a concentration of $2 \mu \mathrm{g} / \mathrm{kg}$ as spiked standard mixture sample) and a reagent blank sample were included.

Liquid chromatography-tandem mass spectrometry (LC-MS/MS)

Sample was injected in the LC system with a flow rate of $450 \mu \mathrm{L} / \mathrm{min}$. The mobile phase was composed of two solutions: A $\left(1.0 \times 10^{-3} \mathrm{~V}\right.$ acetic acid in water) and $\mathrm{B}$ [acetonitrile:solution A $(90: 10 \mathrm{~V} / \mathrm{V})$ ]. Mobile-phase linear gradient program used was: 0-1 min $10 \% \mathrm{~B}, 1-14 \mathrm{~min}$ from 10 to $45 \% \mathrm{~B}, 14-16 \mathrm{~min}$ from 45 to $90 \% \mathrm{~B}, 18-19 \mathrm{~min}$ from 90 to $10 \% \mathrm{~B}$, and $19-22 \mathrm{~min} 10 \% \mathrm{~B}$. The injection volume was $60 \mu \mathrm{L}$; and between injections, the needle was rinsed with a solution of water/acetonitrile 1:1 (V/V).

The entire LC flow was directed into the MS detector between 5 and 12 min by means the Valco valve. A split ratio of about 1:2 was used. The mass spectrometer was operated in positive electrospray ionisation mode (ESI+) using the TurboIonSpray source. Nitrogen was used for curtain, collision, heater, and nebulizer gas at flow rates of $10,5,8$, and $6 \mathrm{~L} / \mathrm{min}$, respectively. The ion source block temperature was set to $T=450{ }^{\circ} \mathrm{C}$, and the electrospray capillary voltage to $5.0 \mathrm{kV}$. Data acquisition was performed in the multiple reaction monitoring (MRM) mode. As the identification of banned substances requires four identification points, according to Commission Decision 2002/657/EC [18], fulfilment criteria were obtained with one precursor ion and two product ions, two transition reactions were monitoring for each nitrofuran metabolite as their nitrophenyl derivative. For each deuterated internal standard, only one transition was controlled. These transitions and their corresponding collision energies are shown in Table 1.

Residue determination

For screening and confirmation purposes, nitrofuran metabolites, as their nitrophenyl derivatives, were detected
Table 1 Ion transitions and corresponding collision energies used for nitrofuran metabolites detection (base peak bolded)

\begin{tabular}{llll}
\hline $\begin{array}{l}\text { Compound as their } \\
\text { nitrophenyl derivatives }\end{array}$ & $\begin{array}{l}\text { Percursor } \\
\text { ion }(\mathrm{m} / \mathrm{z})\end{array}$ & $\begin{array}{l}\text { Product } \\
\text { ions }(\mathrm{m} / \mathrm{z})\end{array}$ & $\begin{array}{l}\text { Collission } \\
\text { energy }(\mathrm{eV})\end{array}$ \\
\hline AOZ & 236 & $\mathbf{1 0 4} ; 134$ & 31,21 \\
AMOZ & 335 & $\mathbf{2 6 2} ; 291$ & 25,17 \\
AHD & 249 & $\mathbf{1 3 4} ; 178$ & 19,23 \\
SEM & 209 & $166 ; \mathbf{1 9 2}$ & 15,17 \\
AOZ-d4 (ISTD) & 240 & 134 & 21 \\
AMOZ-d5 (ISTD) & 340 & 296 & 19 \\
\hline
\end{tabular}

using the most abundant transition of the target analytes (Table 1). Criteria used for detection was the presence of a signal of the controlled transition with a relative retention better than $2.5 \%$ when compared to analytes present on the spiked standard mixture sample. When a representative signal of analyte was observed, the second transition was searched at the same relative retention time. When present, the ion ratio of the two transitions was checked and compared to the one obtained for the same analyte in the spiked standard mixture sample. When ion ratio was identical, after applying recommended tolerances of the Commission Decision 2002/657/EC [18], a positive detection is assumed.

For quantification, calibration curves at five concentrations levels were prepared by spiking blank meat samples with composite standard working solution of analytes (AOZ, AMOZ, AHD, and SEM) at 0.0 (blank sample), 0.5, $1.0,2.0$, and $5 \mu \mathrm{g} / \mathrm{kg}$. These fortified calibration samples and the known positive samples were prepared using the above described procedure of extraction. Calibration curve samples were injected before and after known positive samples, and both data were used to quantitative evaluation. Analyte identification was re-checked following the same criteria described above.

For AMOZ identification and quantification, internal standard AMOZ-d5 was used, and for AHD, SEM and AOZ, AOZ-d4 was utilized. A typical chromatogram is shown in Fig. 2.

\section{Results and discussion}

Method validation

For method validation specificity, linearity, precision (repeatability and within-laboratory reproducibility), accuracy, decision limit $(C C \alpha)$ and detection capability $(C C \beta)$ were determined according to Commission Decision 2002/ 657/EC [18].

Specificity could be demonstrated by analysing 20 blank meat samples before and after spiking at a concentration 
Fig. 2 LC-MS/MS

chromatograms of a blank and b spiked tissue sample at the $1 \mu \mathrm{g} / \mathrm{kg}$ level for AHD, AMOZ, AOZ and SEM (NP nitrophenyl derivatives)
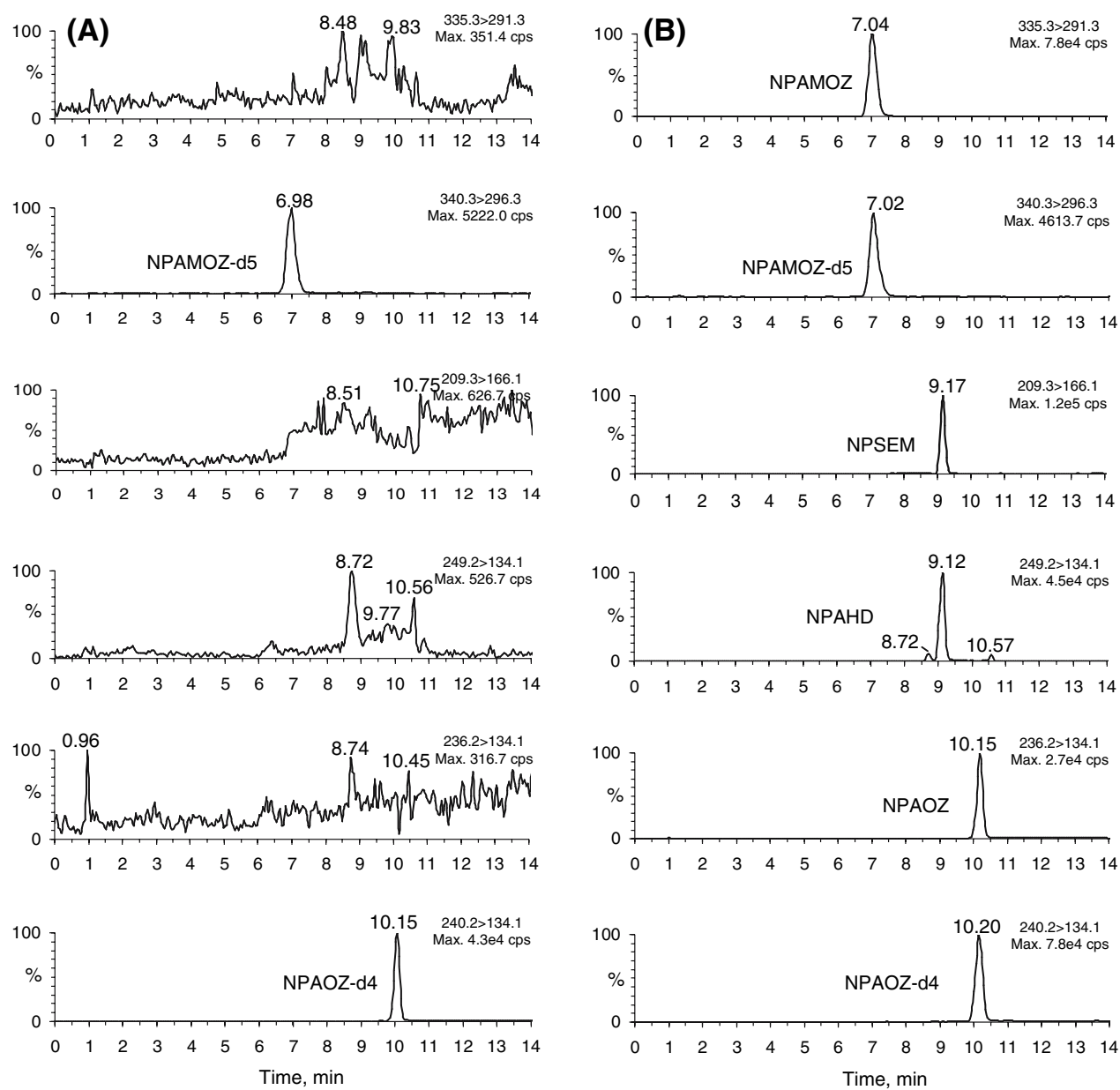

level of $1.0 \mu \mathrm{g} / \mathrm{kg}$. No interfering peaks of eligible size were observed at the retention time windows for the nitrofuran metabolites for the two MRM monitoring transitions of interest for each analyte.

For linearity, accuracy, precision and analytical limits, calibration curves of AOZ, AMOZ, AHD, and SEM were prepared using blank meat samples spiked at 0.0, 0.5, 1.0, 2.0 , and $5.0 \mu \mathrm{g} / \mathrm{kg}$ and submitted to the extraction procedure described above. For each calibration level, six samples were prepared and analysed every day for 3 days. Additionally one standard calibration curve without matrix with the same calibrations levels was prepared and analysed for each day.

Linearity of the chromatographic response was tested with five calibration points in the concentration range of $0.5-5.0 \mu \mathrm{g} / \mathrm{kg}$. The regression coefficients $\left(r^{2}\right)$ for the calibration curves used in the method validation study were $\geq 0.993$ (Table 2).

The accuracy in terms of recovery of the method was measured at $0.5,1.0$, and $2.0 \mu \mathrm{g} / \mathrm{kg}$ for each nitrofuran metabolite and from the most intense transition. The accuracy determined in the three separate assays was between 78 and $103 \%$ (Table 3).
Table 2 Calibration curve parameters obtained in spiked blank meat samples

\begin{tabular}{llll}
\hline $\begin{array}{l}\text { Analyte as their } \\
\text { nitrophenyl derivative }\end{array}$ & $r^{2}$ & $\begin{array}{l}\text { Mean } \\
\text { slope }\end{array}$ & $\begin{array}{l}\text { Mean } \\
\text { intercept }\end{array}$ \\
\hline AOZ & $>0.995$ & 1.532 & 0.160 \\
AMOZ & $>0.996$ & 1.856 & 0.138 \\
AHD & $>0.996$ & 0.864 & 0.198 \\
SEM & $>0.993$ & 1.337 & 0.209 \\
\hline
\end{tabular}

The precision in terms of repeatability and intra-laboratorial reproducibility was evaluated in particular the within and between days variation, by calculating the coefficient of variation $(\mathrm{CV} \%)$ of the mean concentrations results obtained from each analyte at $0.5,1.0$, and $2.0 \mu \mathrm{g} / \mathrm{kg}$ levels of concentration in the 3 days. The values obtained and shown in Table 3 for the $1.0 \mu \mathrm{g} / \mathrm{kg}$ level were lower than $15 \%$ for any of the tested concentrations. Accordingly with Commission Decision 2002/657/EC, coefficient of variation for repeated analysis of spiked or incurred material should not exceed the level obtained after the application of the Horwitz equation, but this equation for mass fractions lower than $100 \mu \mathrm{g} / \mathrm{kg}$ gave unacceptable 
Table 3 Performance characteristics of the method

\begin{tabular}{lllllc}
\hline $\begin{array}{l}\text { Analyte as their } \\
\text { nitrophenyl } \\
\text { derivative }\end{array}$ & $\begin{array}{l}C C \alpha \\
(\mu \mathrm{g} / \mathrm{kg})\end{array}$ & $\begin{array}{l}C C \beta \\
(\mu \mathrm{g} / \mathrm{kg})\end{array}$ & $\begin{array}{l}\text { Accuracy } \\
\text { at } 1 \mu \mathrm{g} / \mathrm{kg}(\%)\end{array}$ & $\begin{array}{l}\text { Repeatability } \\
\text { at } 1 \mu \mathrm{g} / \mathrm{kg}(\% \mathrm{CV})\end{array}$ & $\begin{array}{l}\text { Reproducibility } \\
\text { at } 1 \mu \mathrm{g} / \mathrm{kg}(\% \mathrm{CV})\end{array}$ \\
\hline AOZ & 0.29 & 0.34 & 103 & 4.8 & 9.9 \\
AMOZ & 0.20 & 0.32 & 89 & 6.9 & 10.2 \\
AHD & 0.45 & 0.88 & 92 & 8.5 & 12.6 \\
SEM & 0.15 & 0.46 & 83 & 12.6 & 14.3 \\
\hline
\end{tabular}

high values. As a guideline, a value as low as possible should be reached. It was accepted that values lower than $23 \%$ are fit for the purposed.

Decision limit $(C C \alpha)$ and detection capability $(C C \beta)$ were calculated as stated by Commission Decision 2002/ 657/EC [18] and by ISO 11843 [19]. For $C C \alpha$, with $\alpha=1 \%$, the calculation was performed with the application of the following formula:

$C C \alpha=b+2.33 \mathrm{SD}_{b}$

wherein $b$ is the concentration of the intercept of the regression line and $\mathrm{SD}_{b}$ is the standard deviation from regression line. The $C C \beta$ at $\beta=5 \%$, was then calculated as:

$C C \beta=C C \alpha+1.64 \mathrm{SD}_{C C a}$

wherein $\mathrm{SD}_{C C \alpha}$ is the standard deviation at $C C \alpha$ concentration.

As the minimum required performance limit (MRPL) for nitrofurans was set at $1 \mu \mathrm{g} / \mathrm{kg}$, the values obtained, and summarized in Table 3, were shown to be appropriate.

Furaltadone residues

The analysis of nitrofurans in biological samples under PRMP in 2002 was achieved using two distinguished analytical procedures. The samples collected between the beginning of the year until September $(n=57)$, from various species such as broilers, turkeys, quails, rabbits, bovine, and swine, were submitted to nitrofuran detection by high performance thin layer chromatography (HPTLC) or HPLC-UV/VIS, using the parent compounds as target analytes. All analyzed samples were shown to be compliant.

The remaining samples of the PRMP, collected after September from the same species, were analyzed by the LC-MS/MS method described above and introduced for the routine detection and quantification of nitrofuran metabolites as their nitrophenyl derivatives. From the 226 analyzed meat samples, 78 were demonstrated to be noncompliant for furaltadone metabolite (AMOZ concentration $>1 \mu \mathrm{g} / \mathrm{kg}$ ), of which 61 were from broiler, 11 from turkey, 5 from quail, and 1 from pig species.
The majority of the samples had presented low AMOZ concentrations, reaching average values of $5.4 \mu \mathrm{g} / \mathrm{kg}$ $(n=60)$ in broilers, $5.8 \mu \mathrm{g} / \mathrm{kg}(n=5)$ in quails and $1.9 \mu \mathrm{g} /$ $\mathrm{kg}(n=7)$ in turkeys. A more restricted number of samples revealed much higher concentrations of furaltadone metabolite such as in one broiler sample with a concentration of $63 \mu \mathrm{g} / \mathrm{kg}$, and in four turkeys with $943,141,138$, and $137 \mu \mathrm{g} / \mathrm{kg}$ residue levels. Non-compliant samples involved 46 animal farms, namely broilers $(n=36)$, turkeys $(n=5)$, quails $(n=4)$, and pigs $(n=1)$.

The huge number of non-compliant results obtained led the Portuguese authorities to recognize the existence of an abnormal situation for national food safety and the corresponding actions were taken.

The farms with non-compliant results were placed under official control and subjected to a more stringent check for nitrofuran residues. Meat, feeds, and drinking-water samples were collected and analyzed. A vast set of measures was then introduced, in a special Action Plan presented by Portuguese authorities to the European Commission and approved on 9th May 2003. The application of these measures had involved, among other things, collecting biological samples, feed and drinking water samples covering all existent broilers, layer hens, turkeys, quails, and ducks farms in the country. The Action Plan also includes the control of swine, rabbits, and fish farms, but had a low number of collected samples.

Data obtained from the analysis performed during the first half of 2003 under the application of the above-mentioned measures, are presented in Table 4. All noncompliant samples showed the presence of the furaltadone metabolite, except one, where SEM was detected.

Data referring to non-complaints samples with AMOZ concentration greater than $1 \mu \mathrm{g} / \mathrm{kg}$ were presented in Table 5.

From the comparison of the mean, 5\% trimmed mean, and median obtained, for AMOZ concentration, unmatched values were clear in the case of broilers and turkeys, due to the existence of some mild and extreme outliers (Fig. 3).

To evaluate these outliers, broilers non-complaints samples were divided into three groups in ascendant concentration, who where converted into ranks and submitted to ANOVA test with multiple comparison. It was possible 
Table 4 Analysed samples for nitrofurans metabolites in the first half of 2003 a AMOZ concentration $>1 \mu \mathrm{g} / \mathrm{kg}\left(\mathrm{w} / 1.0 \times 10^{-9}\right)$

\begin{tabular}{lrrr}
\hline Animal/species & $\begin{array}{l}\text { Number of analysed } \\
\text { samples }\end{array}$ & $\begin{array}{l}\text { Number of non-compliant } \\
\text { samples for AMOZ }\end{array}$ & $\begin{array}{l}\text { Non-compliant sample } \\
\text { percentage by animal species }\end{array}$ \\
\hline Broiler & 693 & 260 & 37.5 \\
Chicken & 98 & 29 & 29.6 \\
Turkey & 158 & 81 & 51.3 \\
Quail & 40 & 21 & 52.5 \\
Duck & 50 & 7 & 14.0 \\
Rabbit & 50 & 1 & 2.0 \\
Farm fish & 52 & 18 & 34.6 \\
Sparus aurata & 20 & 1 & \\
Dicenthracus labrax & 27 & 17 & \\
Scophtalmus sp. & 1 & 0 & \\
Salmo truta & 2 & 0 & 0 \\
Salmo salar & 2 & 0 & 0 \\
Ovine & 3 & 0 & 0 \\
Swine & 135 & 0 & \\
Bovine & 25 & 0 &
\end{tabular}

to observe that the mean value of the three groups were significantly different $(p<0.000)$. Identical observations were made from turkeys' obtained data. The correspondent boxplots are shown in Figs. 4 and 5.

These three concentration groups for broilers and turkeys, being statisticaly distinct, probably represent different conditions of animal exposure to furaltadone.

According to the observations of Zuidema et al. [9], the concentrations of AMOZ detected in muscle collected from broilers that were fed a medicated feed $(202 \mathrm{mg} / \mathrm{kg}$ of furaltadone) were $1,000 \mu \mathrm{g} / \mathrm{kg}$ for animals slaughtered 1 day after stopping the compound's administration and diminished to 100 and $60 \mu \mathrm{g} / \mathrm{kg}$ in those animals slaughtered 7-21 days after cessation of medication. Previously, depletion studies of furaltadone metabolite in porcine have shown very similar behaviour [2]. According to these data, the use of furaltadone therapeutic doses leads to the occurrence of high levels of AMOZ in edible tissues. In line with these observations, it was possible that broilers and turkeys that were shown to have higher concentrations of furaltadone metabolite in analysed tissues were probably fed with medicated feed. The middle concentration ranges defined by statistic evaluation from non-compliant samples of broilers and turkeys were difficult to characterize, but suspension of the administration of therapeutic concentrations of the compound, some time before slaughtered, could be one of the reasons, but, the great majority of the non-complaint samples during the nitrofuran crisis showed concentration levels lower than $8.4 \mu \mathrm{g} / \mathrm{kg}$, with a median value of $2.9 \mu \mathrm{g} / \mathrm{kg}$ in the case of broilers, and lower than $15 \mu \mathrm{g} / \mathrm{kg}$, with a median value of $3.5 \mu \mathrm{g} / \mathrm{kg}$, in the case of turkeys (Table 5, Fig. 4).
This situation was also observed by O'Keeffe et al. [20] in pork meat in a retail survey realized under the FoodBRAND project undertaken across 15 European countries in 2002. From the 12 positive samples, ten were purchased in Portugal and contained AMOZ with concentrations ranging from 0.2 to $0.6 \mu \mathrm{g} / \mathrm{kg}$.

According to McCracken et al. [21], low levels of administered furazolidone, nitrofurazone, nitrofurantoin or furaltadone could be the origin of very low tissue-bound nitrofuran metabolite concentrations in broilers' edible tissues; and these detected metabolites showed a linear relation to the quantity of administered nitrofuran.

A frequent cause for these unwanted residues' contamination could be from an accidental feed contamination by carry-over from medicated feed to subsequent unmedicated feed during the animal feed manufacturing process. This possibility was proven through the administration of

Table 5 AMOZ concentration for non-compliant samples collected at the first half of 2003

\begin{tabular}{|c|c|c|c|c|}
\hline \multirow{2}{*}{$\begin{array}{l}\text { Animal } \\
\text { species }\end{array}$} & \multirow{2}{*}{$\begin{array}{l}\text { Number of } \\
\text { non-compliant } \\
\text { samples with } \\
\text { AMOZ }^{\text {a }}\end{array}$} & \multicolumn{3}{|c|}{ AMOZ concentration $\mu \mathrm{g} / \mathrm{kg}$} \\
\hline & & Mean value \pm SD & $\begin{array}{l}5 \% \text { trimmed } \\
\text { mean }\end{array}$ & Median \\
\hline Broiler & 244 & $5.1 \pm 12.9$ & 3.3 & 2.9 \\
\hline Chicken & 29 & $2.3 \pm 1.4$ & 2.1 & 1.7 \\
\hline Turkey & 81 & $46.1 \pm 115.7$ & 24.2 & 3.5 \\
\hline Quail & 21 & $7.7 \pm 5.8$ & 7.3 & 5.7 \\
\hline Duck & 7 & $1.4 \pm 0.18$ & 1.4 & 1.4 \\
\hline Rabbit & 1 & 1.9 & & \\
\hline Farm fish & 18 & $1.5 \pm 0.3$ & 1.4 & 1.4 \\
\hline
\end{tabular}

${ }^{\mathrm{a}}$ AMOZ concentration $>1 \mu \mathrm{g} / \mathrm{kg}\left(\mathrm{w} / 1.0 \times 10^{-9}\right)$ 


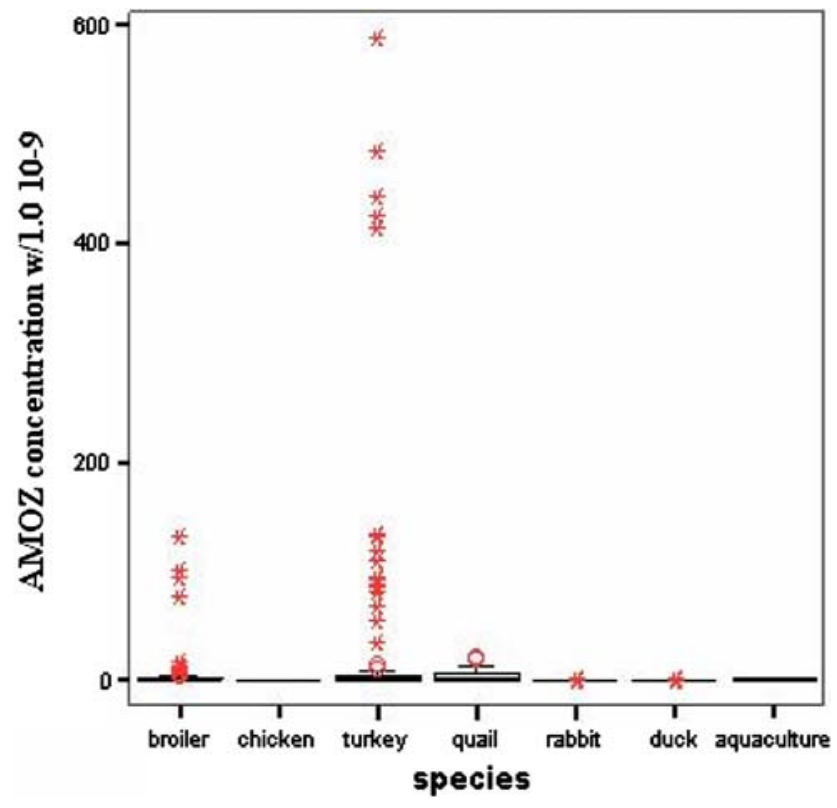

Fig. 3 Boxplot graphic for AMOZ concentrations of non-compliant results obtain in the first half of 2003 for all species tested, showing several mild (open circle) and extreme (asterisks) outliers for turkeys and broilers

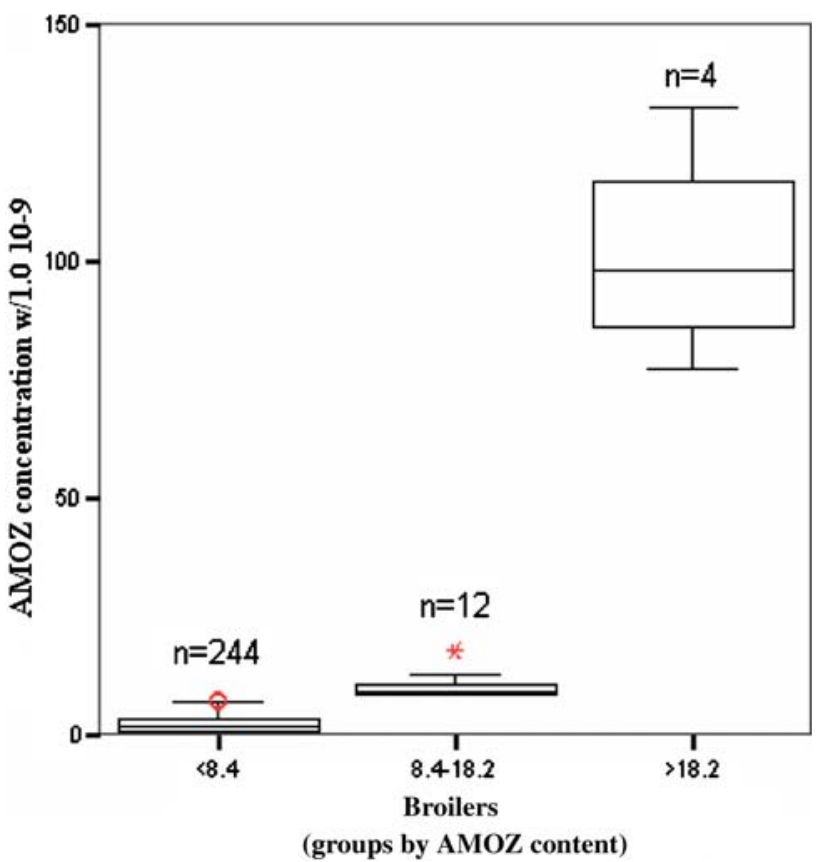

Fig. 4 Boxplot representing the three groups of non-compliant samples in terms of AMOZ concentrations for broilers (mild (open circle) and extreme (asterisks) outliers)

furaltadone at sub-therapeutic doses to broilers, and the observation that even a quantity of furaltadone of about $0.01 \%$ of the former therapeutic dose during 12 days could cause detectable concentrations of AMOZ in edible tissues. Raw material contaminated with nitrofurans' parent compounds or their protein bound metabolites; and exposure

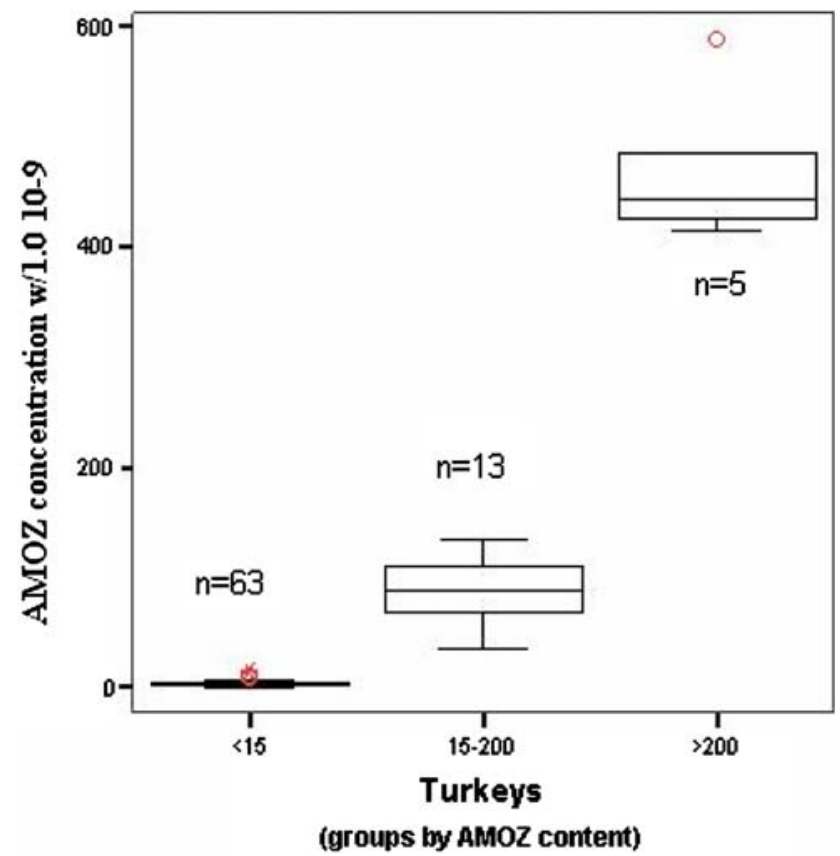

Fig. 5 Boxplot representing the three groups of non-compliant samples in terms of AMOZ concentrations for turkeys (mild (open circle) and extreme (asterisks) outliers)

of unmedicated animals to a contaminated environment constitute known reasons for detectable low-level concentrations of tissue-bound nitrofuran metabolites [2, 19, 22].

From data obtained during the Portuguese nitrofuran crisis it could be easily assumed that a high incidence of furaltadone non-compliant results occurred, especially in poultry meat, varying from 30 to $50 \%$ of analyzed samples. A high level of AMOZ concentration, as referred to above, could be connected to a deliberate illegal administration of furaltadone by medicated feed or by drinking water. However, in the great majority of the cases, observed concentrations of $\mathrm{AMOZ}$ in edible tissues were very low, and could have originated by accidental, unwanted or unintended furaltadone administration.

After September 2003, until present, only one noncomplaint sample for nitrofuran metabolites was found in samples collected on farm and on slaughterhouses as part of the Portuguese plan for residues control.

\section{Conclusions}

The analytical methodology used until the middle of 2002 by the PRMP for detecting residues of nitrofuran compounds by measuring the parent drugs was shown to be inappropriate under EU requirements. It was clear that their application couldn't detect a generalized illicit or inadvertent administration of furaltadone in intensive production of poultry. The effective control of nitrofuran drugs 
was achieved after the introduction of a highly specific and sensitive LC-MS/MS method for long term detection of residues of bound nitrofuran metabolites in edible tissues. So, from data during the Portuguese nitrofuran crisis, it could be easily seen that a high incidence of furaltadone non-compliant results, especially in poultry meat, varied from 30 to $50 \%$ of the analyzed samples. High levels of AMOZ, as it was referred above, could be connected to a deliberate illegal administration of furaltadone by medicated feed or by drinking water. However, for the great majority of the cases, the observed concentration of AMOZ in edible tissues with values lower than $10 \mu \mathrm{g} / \mathrm{kg}$ could have originated in accidental, unwanted, or unintended contamination. Other than these conclusions, and taking into account that the detection of nitrofuran metabolites in food animal's products was an offence to UE legislation, a systematic procedure to evaluate nitrofuran in feeds and in drinking water for animal production, namely poultry production, was strongly recommended, in order to avoid other similar outcomes that was caused by the so called "Portuguese nitrofuran crisis".

Acknowledgments The authors are grateful to Dr. Humberto Ferreira for his assistance on statistic evaluation of the data and to Mr. Carlos Gonçalves for the practical assistance.

\section{References}

1. Herrlich P, Schweiger M (1976) Proc Natl Acad Sci USA 73:3386-390

2. Cooper KM, Mulder PPJ, van Rhijn JA, Kovacsics L, McCracken RJ, Young PB, Kennedy DG (2005) Food Addit Contam 22:406414. doi:10.1080/02652030512331385218

3. Ali BH (1999) Vet Res Commun 23:343-360. doi:10.1023/ A: 1006333608012

4. Hoogenboom LAP, van Bruchem GD, Sonne K, Enninga IC, van Rhijn JA, Heskamp H, Huveneers-Oorsprong MBM, van der
Hoeven JCM, Kuiper HA (2002) Environ Toxicol Pharmacol 11:273-287

5. Olive PL, McCalla DR (1997) Chem Biol Interact 16:223-233. doi:10.1016/0009-2797(77)90131-4

6. Regulation (EEC) 2901/93, of 18 October 1993. Off J Eur Communities L264:1-4

7. Regulation 1442/95, of 26 June 1995. Off J Eur Communities L143:26-30

8. Vroomen LHM, Berghmans MJC, van Leeuwen P, van der Struijs TDB, Vries PHU, Kuiper HA (1986) Food Addit Contam 3:331346

9. Zuidema T, van Rhijn JA, Schat B, Mulder PPJ, Bolck YJC, Hoogenboom LAP, Kennedy DG (2004) Proceedings of the Euroresidue V conference, Noordewijkerhout, The Netherlands. 10-12 May, 2004, pp 996-1001

10. Nouws JFM, Laurensen J (1990) Tijdschr Diergeneesk 116:359_ 362

11. Hoogenboom LAP, van Kammen M, Berghmans MCJ, Koeman JH, Kuiper HA (1991) Food Chem Toxicol 29:321-328

12. Hoogenboom LAP, Berghmans MCJ, Polman THG, Parker R, Shaw IC (1992) Food Addit Contam 9:623-630

13. McCracken RJ, Kennedy DG (1997) J Chromatogr B 691:87-94

14. McCracken RJ, Blanchflower WJ, Rowan C, McCoy MA, Kennedy DG (1995) Analyst 120:2347-2351. doi:10.1039/ AN9952002347

15. Horne E, Cadogan A, O'Keeffe M, Hoogenboom LAP (1996) Analyst 121:1463-1468. doi:10.1039/AN9962101463

16. Leitner A, Zollner P, Lindner W (2001) J Chromatogr A 939:4958

17. Verdon E, Couedor P, Sanders P (2007) Anal Chim Acta 586:336-347. doi:10.1016/j.aca.2007.01.024

18. Commission Decision 2002/657/EC of 12 August 2002 Off $\mathbf{J}$ Communities L221:8-36

19. ISO 11843-2:2000. Capability of detection-part 2: methodology in the linear calibration case (2000)

20. O'Keeffe M, Conneely A, Cooper KM, Kennedy DG, Kovacsics L, Fodor A, Mulder PPJ, van Rhijn JA, Trigueros G (2004) Anal Chim Acta 520:125-131. doi:10.1016/j.aca.2004.04.053

21. McCracken RJ, van Rhijn JA, Kennedy DG (2004) Proceedings of the Euroresidue V Conference, Noordewijkerhout, The Netherlands 10-12 May, 2004, pp 655-660

22. McCracken RJ, McCoy MA, Kennedy DG (1997) Food Addit Contam 3:287-294 